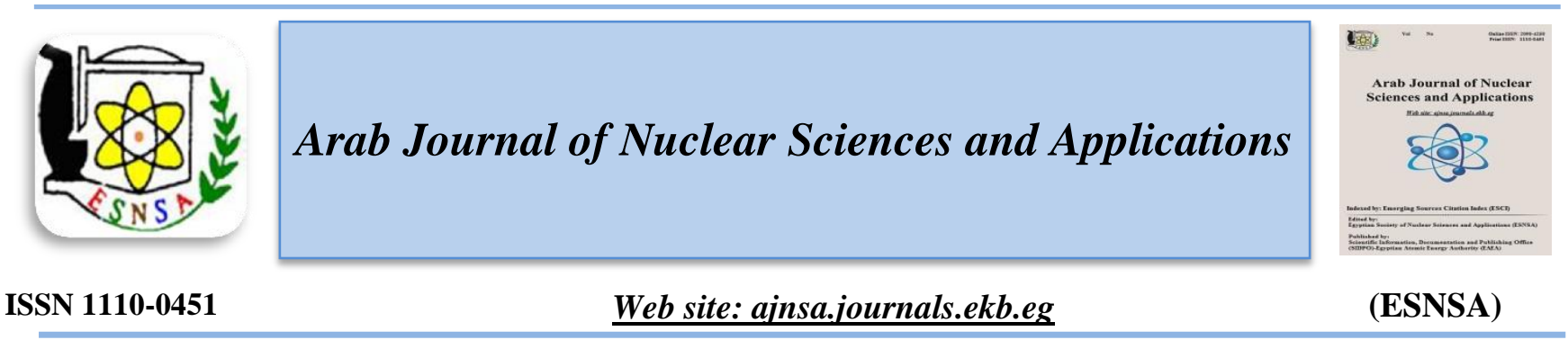

\title{
Characteristics of Dielectric Behavior and AC Electrical Conductivity of Bulk Antimony Sulfide $\left(\mathbf{S b}_{2} \mathbf{S}_{3}\right)$
}

\author{
H. E. A. El-Sayed, H. A. M. Ali", G. F. Salem, M. A. Mahmoud \\ Physics Department, Faculty of Education, Ain Shams University, Cairo, Egypt
}

Received $9^{\text {th }}$ April 2020 The structural features and morphology of investigated $\mathrm{Sb}_{2} \mathrm{~S}_{3}$ powder were analyzed using $\mathrm{X}$-ray Accepted $14^{\text {th }}$ Sept. diffraction and scanning electron microscope techniques. The dependence of dielectric properties and ac 2020 conductivity of bulk $\mathrm{Sb}_{2} \mathrm{~S}_{3}$ as pellet on both of frequency $\left(10^{2}-10^{6} \mathrm{~Hz}\right)$ and temperature $(303-393 \mathrm{~K})$ were studied. The dielectric constant (121.2-45.8) and dielectric loss (53.3-0.89) displayed noticeable dependence on frequency and in the investigated range of temperature 303-393 K. The frequency dependence of ac conductivity $\sigma_{\mathrm{ac}}(\omega)$ follows up the power relation; $\sigma_{\mathrm{ac}}(\omega)=\mathbf{G} \omega^{\mathrm{s}}$. The frequency exponent $s$, diminished with the rise in temperature, implying that the correlated barrier hopping (CBH) is the predominant conduction mechanism. The ac conductivity exhibited a thermally activated nature. The localized states $N\left(E_{F}\right)$ values were recorded in the order of $10^{18} \mathrm{eV}^{-1} \cdot \mathrm{cm}^{-3}$ at specific temperatures for frequency of $800 \mathrm{~Hz}$. Activation energy $\Delta \mathrm{E}$, calculated at different frequencies indicates a decrease from $117 \mathrm{meV}$ to $89 \mathrm{meV}$ with the increase in the frequency.

Keywords: Antimony sulfide, AC electrical conductivity, Dielectric properties, Density of localized states

\section{Introduction}

The Antimony sulfide, $\mathrm{Sb}_{2} \mathrm{~S}_{3}$, is one of $\mathrm{V}-\mathrm{VI}$ semiconductor materials and it exists in nature as mineral stibnite [1,2]. Antimony sulfide is one of the most promising semiconductor functional materials because of its characteristic structure $[3,4]$ with orthorhombic crystal structure [1]. It is an n-type semiconductor [5] and has a considerable attention for usage in the electronic applications as photoconductive detectors [6], photo-catalysis [7], photovoltaics [8], thermoelectric devices [9]. Petzelt and Grigas [10] measured Far infrared reflectivity of $\mathrm{Sb}_{2} \mathrm{~S}_{3}$ single crystals in the spectral region $25-400 \mathrm{~cm}^{-1}$ and temperature region 100 $400 \mathrm{~K}$ in polarized light. The results suggested that $\mathrm{Sb}_{2} \mathrm{~S}_{3}$ was polar in the whole temperature region investigated.
The large anisotropy of the structure for $\mathrm{Sb}_{2} \mathrm{~S}_{3}$ crystal showed effects on the physical properties. The static dielectric constant parallel to the chain axis is more than ten times larger compared to that prependicular to the same axis [11-13]. Due to its excellent photoconductivity, $\mathrm{Sb}_{2} \mathrm{~S}_{3}$ garbs a wide attention for its potential applications in solar energy conversions [14,15] and as an absorber layer in solar cells $[1,16,17]$. Messina et al. [18] prepared $\mathrm{Sb}_{2} \mathrm{~S}_{3}$ thin films for photovoltaic cell. Additionally, it showed particular optical properties; high refractive index [19], and high optical absorption coefficient $\left(\alpha>10^{4} \mathrm{~cm}^{-1}\right)$ [2022].

Ghosh and Varma [23] studied some optical properties of amorphous and crystalline $\mathrm{Sb} 2 \mathrm{~S} 3$ thin film. They observed that the amorphous $\mathrm{Sb}_{2} \mathrm{~S}_{3}$ films had values for imaginary and real parts of the

Corresponding author: hend2061@yahoo.com

DOI: 10.21608/ajnsa.2020.27596.1344

CScientific Information, Documentation and Publishing Office (SIDPO)-EAEA 
dielectric constant much less than the polycrystalline films. The optical gap in amorphous material observed at $1.7 \mathrm{eV}$ compared to the apparently direct band gap of $1.88 \mathrm{eV}$ observed in crystalline materials. Also, it was found that the electrical resistivity of the $\mathrm{Sb}_{2} \mathrm{~S}_{3}$ thin films decreased from $10^{8}$ to $10^{6} \Omega$.cm after plasma treatments.

The present work aims at studying the dependence of dielectric properties $\left(\varepsilon_{1}\right.$ and $\left.\varepsilon_{2}\right)$ and ac conductivity $\left(\sigma_{\mathrm{ac}}\right)$ of bulk $\mathrm{Sb}_{2} \mathrm{~S}_{3}$ on both frequency and temperature. The frequency range is $\left(10^{2}-10^{6}\right.$ $\mathrm{Hz}$ ) and temperature range is $303-393 \mathrm{~K}$. The predominant mechanism for ac conduction is specified. The behavior for electric modulus $\left(\mathrm{M}^{\prime}\right.$ and $\mathrm{M}^{\prime \prime}$ ) of bulk $\mathrm{Sb}_{2} \mathrm{~S}_{3}$ is also investigated.

\section{Experimental technique}

The powder of $\mathrm{Sb}_{2} \mathrm{~S}_{3}$ was purchased from BALZERS. Elemental analysis was carried out using Quanta FEG- 250 SEM instrument for energy dispersion analysis spectrum. X-Ray diffraction, XRD, technique was utilized for analyzing the structural properties of the Figure (2) displays the XRD pattern of $\mathrm{Sb}_{2} \mathrm{~S}_{3}$. It has various diffraction peaks with different intensities, illustrating that the $\mathrm{Sb}_{2} \mathrm{~S}_{3}$ has a polycrystalline nature. The position of the peaks appeared in the diffractogram of the powder sample agreement with JCPD card No. (87-1135) [26]. The structural features are consistent with an orthorhombic system with lattice parameters $a=14.20 \AA, b=11.47$ $\AA$, c=7.47 $\AA$ and density of $3.709 \mathrm{~g} / \mathrm{cm}^{3}$. The major diffraction peak corresponds to the preferred orientation of (401). In other studies, preferred orientation plane is (130) as published in the literature $[1,27,28]$. Figure (3a) shows the image of the surface morphology of $\mathrm{Sb}_{2} \mathrm{~S}_{3}$. The powder of $\mathrm{Sb}_{2} \mathrm{~S}_{3}$ showed particles of irregular shape which distributed over the surface in agglomerates as shown through the higher-magnification SEM image (Fig. 3(b)).

investigated $\mathrm{Sb}_{2} \mathrm{~S}_{3}$. XRD pattern was detected using X-ray diffractometer (Philips, model x`pert) with the characteristic $\mathrm{CuK}_{\alpha}$ radiation.

A compressed pellet was obtained from grounded $\mathrm{Sb}_{2} \mathrm{~S}_{3}$ powder. Scanning electron microscopy was performed using SEM microscope Quantum FEG 250. The compression was under a pressure of $2 \times 10^{8} \mathrm{~N} / \mathrm{m}^{2}$. The pellet thickness and radius were $1.05 \mathrm{~mm}$ and $5 \mathrm{~mm}$, respectively. Two silver electrodes were made on both sides of the pellet by using thermal evaporation method. High-vacuum coating unit, Edwards 306A- England was used for the deposition under pressure of $10^{-4} \mathrm{~Pa}$ with a deposition rate of $2.5 \mathrm{~nm} / \mathrm{s}$. The $\mathrm{AC}$ and dielectric measurements for the investigated sample were carried out using a programmable automatic RLC bridge, Hioki model 3532 Hitester, in the frequency ranges $\left(10^{2}-10^{6} \mathrm{~Hz}\right)$. The temperature was measured using a thermocouple over temperature range (303-393K). The values of capacitance, $\mathrm{C}$, and loss tangent, tan $\delta$ measuring from LCR Bridge were used to calculate the dielectric constant and dialectic loss as : $\varepsilon_{1}=$ $\mathrm{Cd} / \varepsilon_{0} \mathrm{~A}$ and $\varepsilon_{2}=\varepsilon_{1} \tan \delta$, respectively, where $\mathrm{d}$ is the thickness, $\mathrm{A}$ is the cross section area of the pellet and $\varepsilon_{0}$ is the permittivity of free space. Additionally, ac conductivity of the sample $\left(\sigma_{\mathrm{ac}}\right)$ was estimated from the relation: $\sigma_{\mathrm{ac}}=\omega \varepsilon_{\mathrm{o}} \varepsilon_{2}[24,25]$ where $\omega$ is the angular frequency.

\section{RESULTS AND DISCUSSION}

\section{Structural properties of $\mathrm{Sb}_{2} \mathrm{~S}_{3}$}

Figure (1) shows the EDX spectrum recorded on the powder of $\mathrm{Sb}_{2} \mathrm{~S}_{3}$, whose peaks are assigned to $\mathrm{Sb}$ and $\mathrm{S}$. A small peak for oxygen was observed as faint impurity as formation of antimony oxides during the preparation of the product. The EDX analysis of the $\mathrm{Sb}_{2} \mathrm{~S}_{3}$ shows that the atomic percentage of $(\mathrm{Sb} \approx 32.75 \%)$ is smaller than that of ( $S \approx 49.03 \%$ ), where the ratio of $\mathrm{Sb} / \mathrm{S}$ to be 0.667 , as expected.

\section{Frequency and temperature dependencies of dielectric properties}

The study of dielectric properties for materials is an important to give information about the conduction processes. The complex permittivity is explained according to the following equation [29]:

$$
\varepsilon^{*}(\omega)=\varepsilon_{1}(\omega)-\mathrm{i} \varepsilon_{2}(\omega)
$$

The frequency and temperature dependences of the dielectric constant $\varepsilon_{1}(\omega)$ and dielectric loss $\varepsilon_{2}$ $(\omega)$ were studied for bulk $\mathrm{Sb}_{2} \mathrm{~S}_{3}$ in the frequency ranges $\left(10^{2}-10^{6} \mathrm{~Hz}\right)$ and temperature range (303393) K. Fig.4(a,b) illustrate the frequency dependence of the dielectric constant $\varepsilon_{1}(\omega)$ and dielectric loss $\varepsilon_{2}(\omega)$ at the different temperatures. As seen, in the investigated range of temperatures, the dielectric constant showed values in the range from 121.2 to 45.8 and dielectric loss showed 
values in the range from 53.3 to 0.89 . The higher values of $\varepsilon_{1}(115 \pm 5)$ and $\varepsilon_{2}(36 \pm 17)$ appeared at While they decreased and approaching a constant value at high frequencies as $46 \pm 1$ for $\varepsilon_{1}$ and 1.32 \pm 0.4 for $\varepsilon_{2}$ in the investigated range of temperatures. The decrease of $\varepsilon_{1}(\omega)$ probably refer to the contribution of many components of polarization; ionic, electronic, interface and orientation polarizations [30-32]. At greater frequencies, the dipole unable to follow up the field, and the orientation polarization stopped. Thus, the value of $\varepsilon_{1}(\omega)$ may be assigned to the space charge or interfacial polarization as observed in studies reported by other authors [33,34]. On the other hand, the behavior of $\varepsilon_{2} \quad(\omega)$ at low frequencies is due to the migration of ions in the material. After average increase in frequency, value depends on the contribution of ions jump, conduction loss of ions migration, and ions low frequencies and in the investigated range of temperatures.

polarization loss. At higher frequency, ion vibrations give the source of dielectric loss and $\varepsilon_{2}$ exhibited a lower value.

Figure 5(a,b) represents temperature dependence of $\varepsilon_{1}(\omega)$ and $\varepsilon_{2}(\omega)$ at the certain frequencies. Both $\varepsilon_{1}(\omega)$ and $\varepsilon_{2} \quad(\omega)$ increase with increasing temperature at various frequencies. At low temperatures, dipoles in polar materials cannot orient themselves. As the temperature increases, the orientation of dipoles becomes easier where it gave an increase in the orientational polarization and $\varepsilon_{1}$. The raising in the value of $\varepsilon_{2}(\omega)$ with the raise in temperature can be explained according to Stevels [32,35], who divided the relaxation phenomena into three parts, conduction loss, dipole loss and vibrational loss.

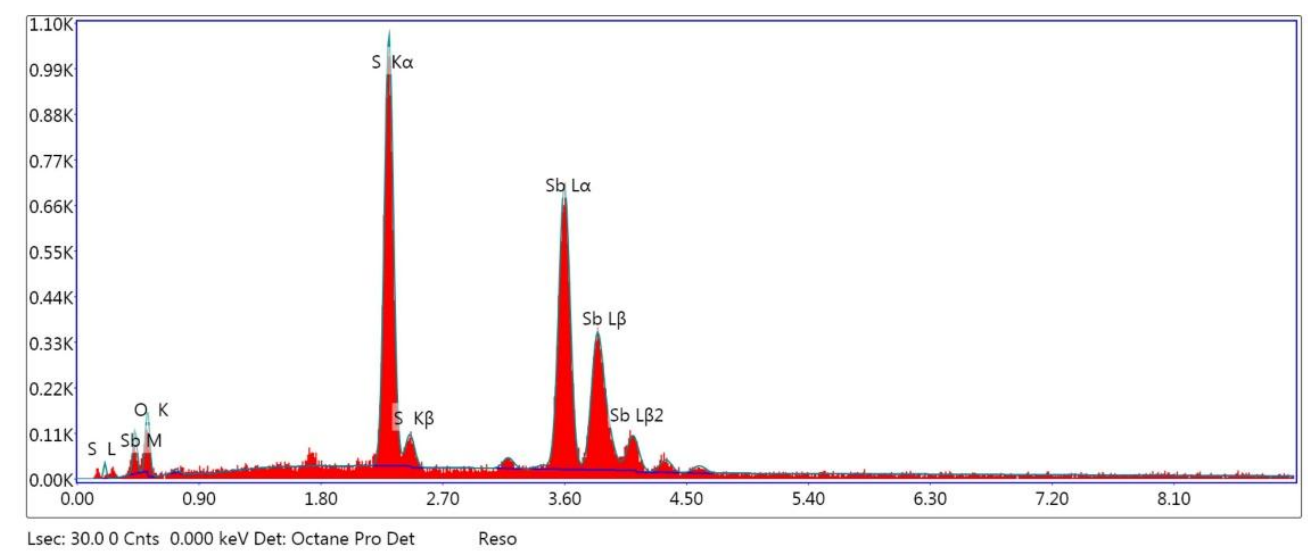

Fig. (1): EDX spectrum of $\mathrm{Sb}_{2} \mathrm{~S}_{3}$ 


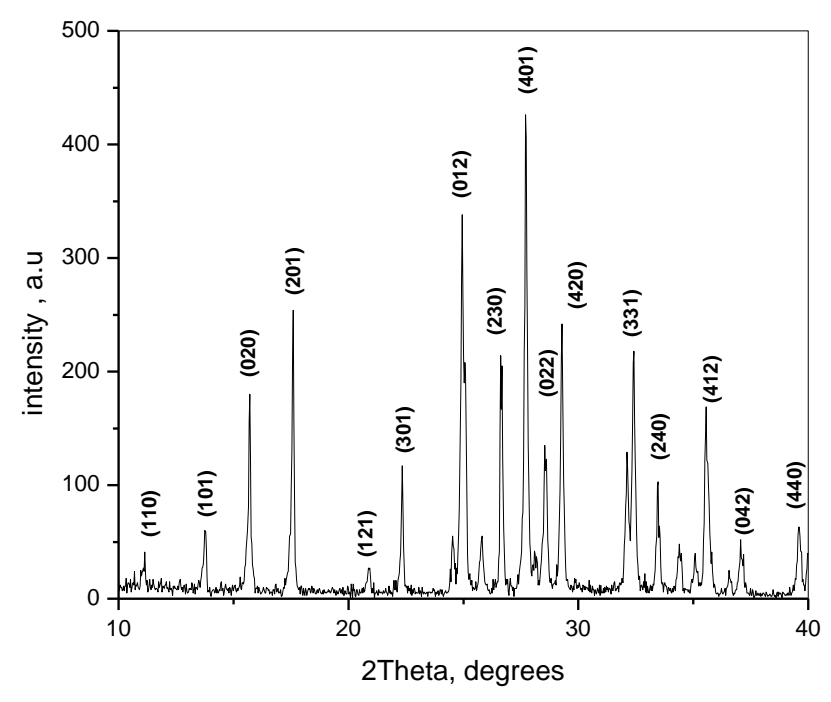

Fig. (2): XRD pattern of $\mathrm{Sb}_{2} \mathrm{~S}_{3}$ in the powder form

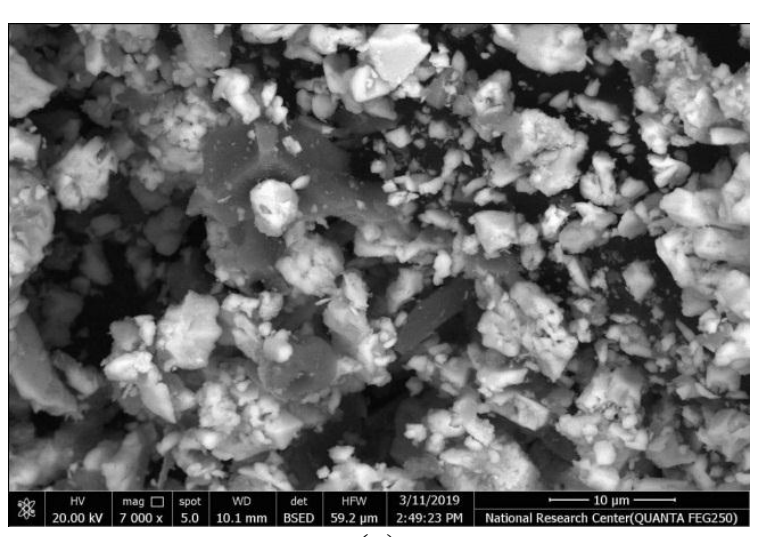

(a)

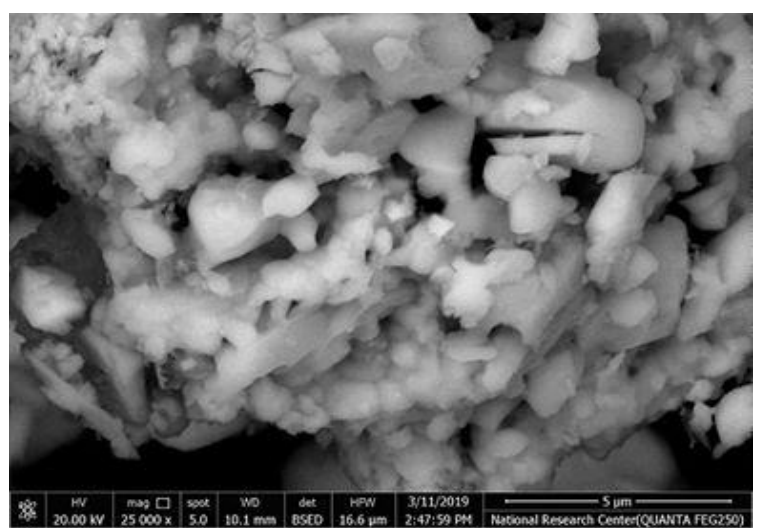

(b)

Fig. (3): SEM image of $\mathrm{Sb}_{2} \mathrm{~S}_{3}$ at Magnification of (a) 7000x and (b) 25000x
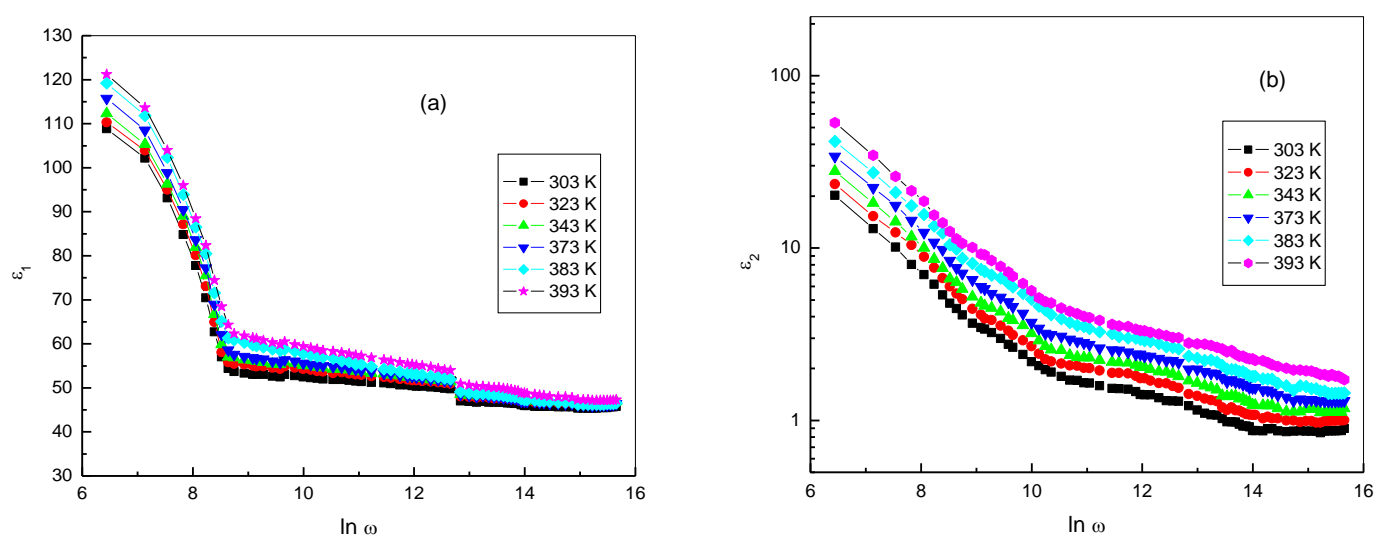

Fig. (4): Frequency dependence of (a) dielectric constant $\varepsilon_{1}(\omega)$ and (b) dielectric loss $\varepsilon_{2}(\omega)$ for $\mathrm{Sb}_{2} \mathrm{~S}_{3}$ at different temperatures 

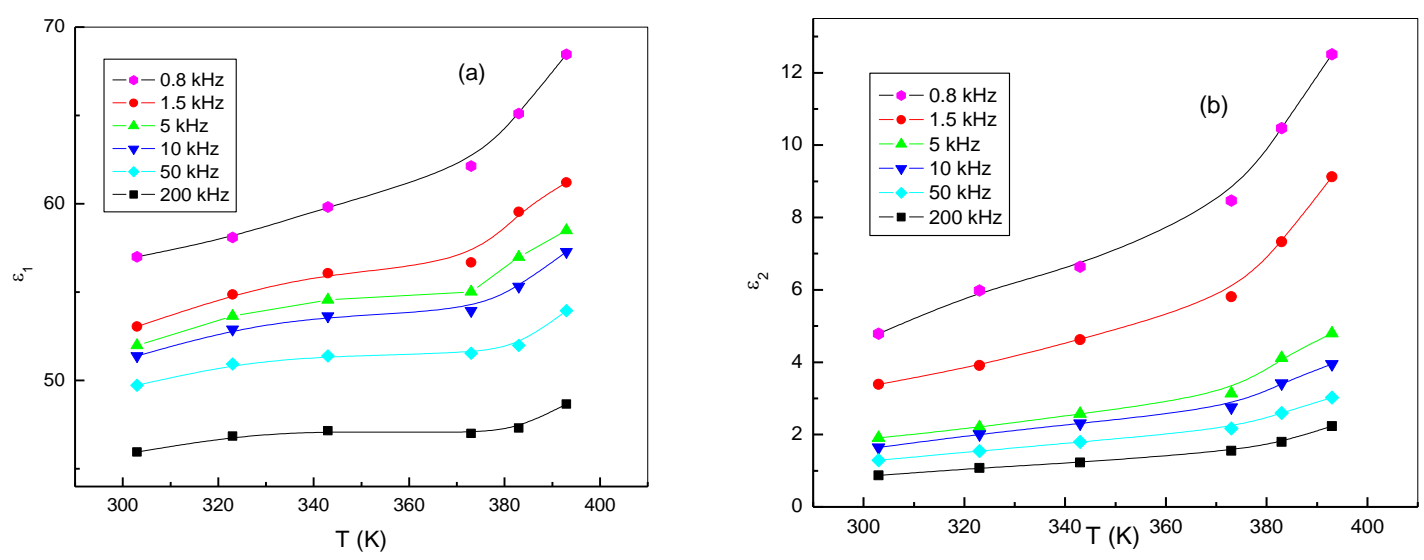

Fig. (5): Temperature dependence (a) dielectric constant $\varepsilon_{1}(\omega)$ and (b)dielectric loss $\varepsilon_{2}(\omega)$ for $\mathrm{Sb}_{2} \mathrm{~S}_{3}$ at different frequencies

\section{Electric modulus spectrum}

The electrical relaxation of bulk $\mathrm{Sb}_{2} \mathrm{~S}_{3}$ can be obtained from the studied electric modulus [36, 37]. The complex of electric modulus $M^{*}$ is given by

$$
M^{*}(\omega)=M^{\prime}+i M^{\prime \prime}
$$

(3)

$$
\mathrm{M}^{\prime}=\frac{\varepsilon_{1}}{\varepsilon_{1}^{2}+\varepsilon_{2}^{2}} \quad, \quad \mathrm{M}^{\prime \prime}=\frac{\varepsilon_{2}}{\varepsilon_{1}^{2}+\varepsilon_{2}^{2}}
$$

Where, $\mathrm{M}^{\prime}$ and $\mathrm{M}^{\prime \prime}$ are the real and imaginary parts of the dielectric modulus, respectively. The frequency dependence of the real and imaginary parts of the electric modulus $\mathrm{M}^{\prime}$ and $\mathrm{M}^{\prime \prime}$ for bulk $\mathrm{Sb}_{2} \mathrm{~S}_{3}$ at different temperatures are shown in Fig. 6, 7. It is noted that $\mathbf{M}^{\prime}$ has small values at low frequencies, $8.8 \times 10^{-3}$ at $303 \mathrm{~K}$ and $6.9 \times 10^{-3}$ at $393 \mathrm{~K}$. It increases with the increase in frequency at different temperatures. The imaginary part of electric modulus $\mathrm{M}^{\prime \prime}$ decreases at low frequencies, then it increases with raising the frequency which reaches a maximum value of $1.49 \times 10^{-3}$ at $303 \mathrm{~K}$ and $2.66 \times 10^{-3}$ at $393 \mathrm{~K}$ and after that it decreases with the further raise in frequency values.

\section{AC conductivity}

$\mathrm{AC}$ conductivity is an important factor which gives information about the transport phenomenon in materials, also it is a good method for determining the hopping dynamics of ions. The ac conductivity $\left(\sigma_{\mathrm{ac}}\right)$ showed dependence on the frequency of the applied field as a power relation [38]:

$$
\sigma_{\mathrm{ac}}(\omega)=\mathrm{G} \omega^{\mathrm{s}}
$$

Where, $G$ is a pre-factor that depends on temperature and composition, and $\mathrm{s}$ is the frequency exponent that can take the value range from $0<\mathrm{s} \leq 1$ [39]. Figure (8) presents the variation of $\ln \sigma_{\mathrm{ac}}$ for bulk $\mathrm{Sb}_{2} \mathrm{~S}_{3}$ versus $\ln \omega$ at different temperatures. From this Figure, the ac conductivity for bulk $\mathrm{Sb}_{2} \mathrm{~S}_{3}$ increases gradually with increasing the frequency. Then, it shows a great increase in its values. The frequency exponent (s) is calculated for the different temperatures (300-393 K). The dependence of $\mathrm{s}$ on temperature is seen in Fig.(9). It was observed that $s$ values decreased with the increase in the temperature. This result for the frequency exponent is consistent with the observed for amorphous fast ion conducting $\mathrm{Ag}_{2} \mathrm{~S}-\mathrm{Sb}_{2} \mathrm{~S}_{3}$ materials [40] and $\mathrm{Sb}_{2} \mathrm{~S}_{3}$ films [33] and $\mathrm{Sb}_{2} \mathrm{~S}_{3}$ sprayed thin film [41]. The behavior of the frequency exponent is used to determine the type of the dominant mechanism for ac conduction [42]. Various models; quantum mechanical-tunneling model $[43,44]$, small polaron tunneling model $[44,45]$, correlated barrier hopping $(\mathrm{CBH})$ model and large polaron tunneling model [46-48] have been suggested for ac conduction mechanisms in different materials. Depending on the obtained results for bulk $\mathrm{Sb}_{2} \mathrm{~S}_{3}$ 
under investigation (Fig.9), the mechanism of ac conduction follows CBH model [47] as observed in Table (1) for other samples of $\mathrm{Sb}_{2} \mathrm{~S}_{3}$. On Austin-Mott formula [49], based on CBH model, ac conductivity expressed as:

$$
\sigma_{a c}(\omega)=\frac{\pi}{3}\left[\left(N\left(E_{F}\right)\right]^{2} k_{B} T e^{2} \alpha^{-5} \omega\left[\ln \left(v_{p} / \omega\right)\right]^{4}\right.
$$

Where, $\mathrm{N}\left(\mathrm{E}_{\mathrm{F}}\right)$ is the density of localized states, $\mathrm{k}_{\mathrm{B}}$ is the Boltzmann's constant, e is the electronic charge, $\alpha$ is the exponential decay parameter of localized states wave functions and $v_{p}$ is the frequency of the phonons. In $\mathrm{CBH}$ mechanism, $\sigma_{\mathrm{ac}}$ is interpreted according to hopping of electrons between pairs of localized states at the Fermi level $\mathrm{N}\left(\mathrm{E}_{\mathrm{F}}\right)$. By assuming $v_{\mathrm{p}}=10^{12} \mathrm{~Hz}$ and $\alpha^{-1}=10 \AA$ [50], $\mathrm{N}\left(\mathrm{E}_{\mathrm{F}}\right)$ is calculated at different temperatures for frequency of $800 \mathrm{~Hz}$ and recorded in Table (2). The values of $\mathrm{N}\left(\mathrm{E}_{\mathrm{F}}\right)$ for bulk $\mathrm{Sb}_{2} \mathrm{~S}_{3}$ increases from $8.69 \times 10^{18}$ to $12.09 \times 10^{18} \mathrm{eV}^{-1} \cdot \mathrm{cm}^{-3}$ with the increase in the temperatures from $303 \mathrm{~K}$ to $393 \mathrm{~K}$. These values of $\mathrm{N}\left(\mathrm{E}_{\mathrm{F}}\right)$ are compared with other studies as seen in Table (2). Figure (10) shows the variation of ac conductivity for bulk $\mathrm{Sb}_{2} \mathrm{~S}_{3}$ with
$1000 / T$ at different frequencies. It was observed that $\sigma_{\mathrm{ac}}$ increased linearly with the increase in the temperature. This behavior was attributed to the increase in the number of charges, which makes hopping increases [51]. This suggested that the ac conductivity for bulk $\mathrm{Sb}_{2} \mathrm{~S}_{3}$ was a thermally activated process with an activation energy $\Delta \mathrm{E}$. The value of $\Delta \mathrm{E}$ for ac conduction was calculated from the Arrhenius relation asfollows [52]:

(6)

$$
\sigma_{\mathrm{ac}} \quad=\quad \sigma_{\mathrm{p}} \quad\left(-\Delta \mathrm{E} / \mathrm{k}_{\mathrm{B}} \mathrm{T}\right)
$$

Where, $\sigma_{\mathrm{p}}$ is a pre-exponential constant. The frequency dependence of $\Delta \mathrm{E}$ for $\mathrm{Sb}_{2} \mathrm{~S}_{3}$ is shown in Fig. (11). $\Delta \mathrm{E}$ decreased with increasing frequency from $117 \mathrm{meV}$ at $800 \mathrm{~Hz}$ to $89 \mathrm{meV}$ at $200 \mathrm{kHz}$, which refers to the increase of the electronic jumps between the localized states as the applied frequency rises [53]. This emphasizes that the hopping conduction is the prevalent mechanism for ac conduction in $\mathrm{Sb}_{2} \mathrm{~S}_{3}$. A similar trend was observed in $\mathrm{Sb}_{2} \mathrm{~S}_{3}$ thin films [33].

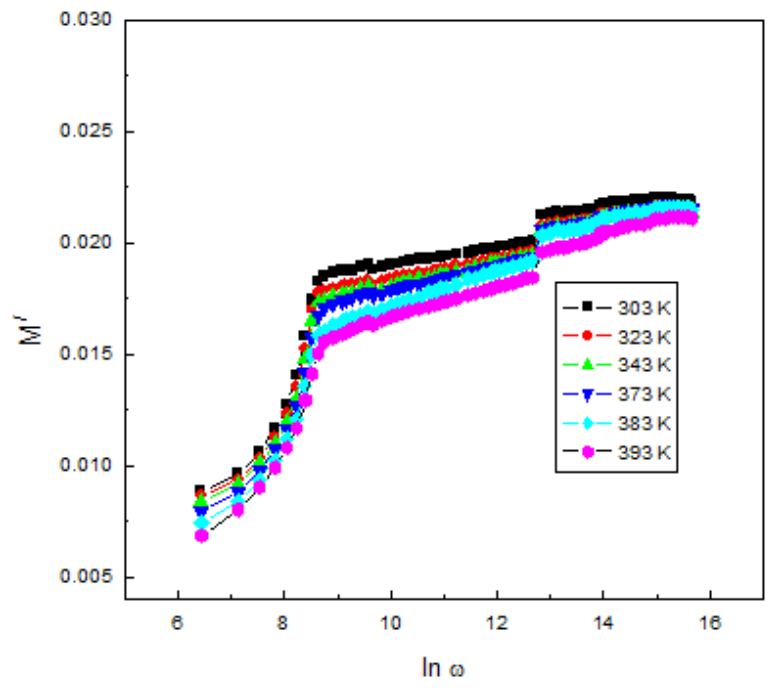

Fig. (6): Frequency dependence real part of dielectric modulus $\mathrm{M}^{\prime}$ for $\mathrm{Sb}_{2} \mathrm{~S}_{3}$ at different temperatures

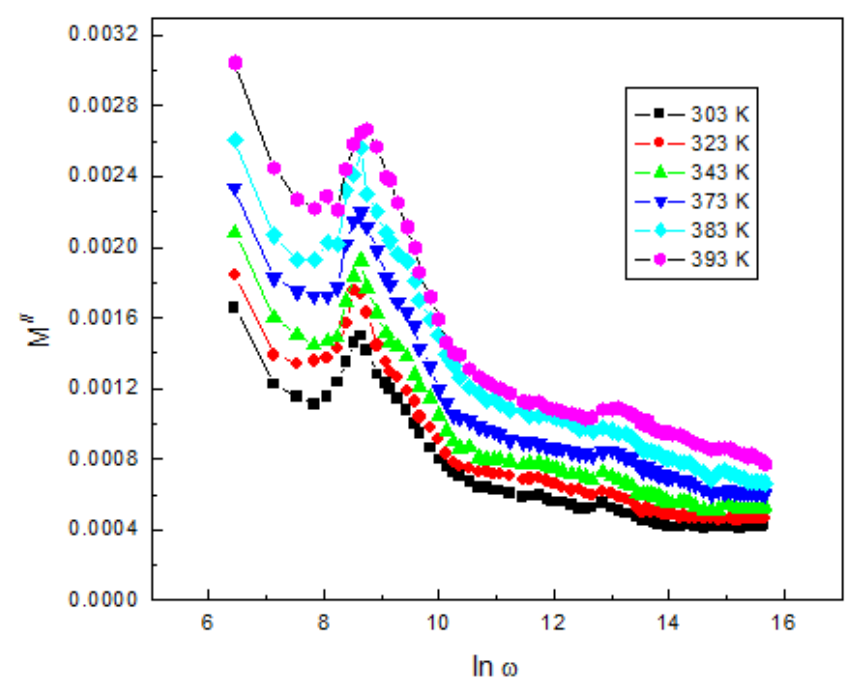

Fig. (7): Frequency dependence imaginary parts of dielectric modulus $M^{\prime \prime}$ for $\mathrm{Sb}_{2} \mathrm{~S}_{3}$ at different temperatures 


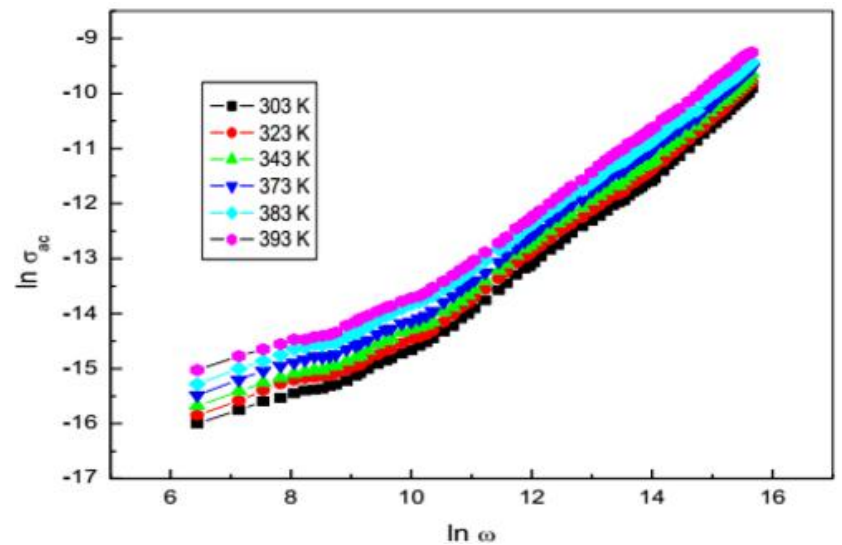

Fig. (8): Variation of $\ln \sigma_{\mathrm{ac}}(\omega)$, with $\ln \omega$ for $\mathrm{Sb}_{2} \mathrm{~S}_{3}$ at different temperatures

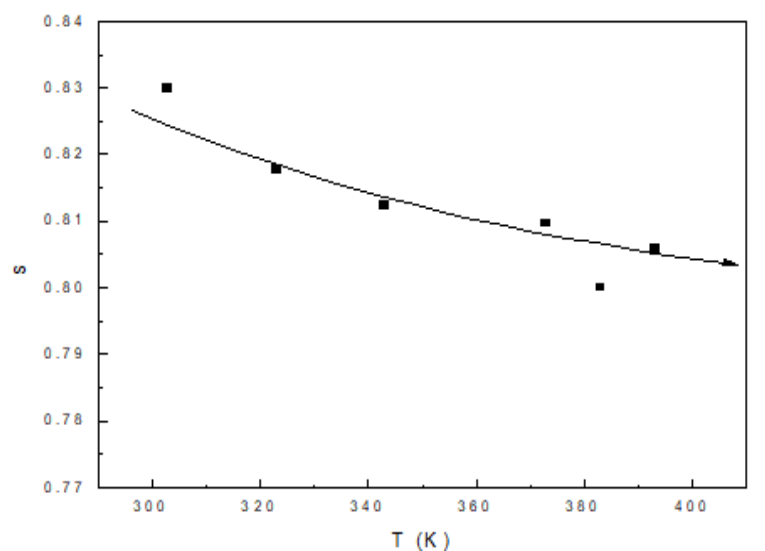

Fig. (9): Temperature dependence of frequency exponent(s) for $\mathrm{Sb}_{2} \mathrm{~S}_{3}$

Table (1): Results of bulk $\mathrm{Sb}_{2} \mathrm{~S}_{3}$ compared with other studies

\begin{tabular}{|c|c|c|c|c|c|}
\hline $\begin{array}{l}\text { Materials } \\
\text { condition }\end{array}$ & $\begin{array}{c}\text { Temperature } \\
\text { range }(\mathbf{K})\end{array}$ & $\begin{array}{l}\text { Frequency } \\
\text { range }(\mathrm{Hz})\end{array}$ & $\begin{array}{c}\text { Frequency } \\
\text { exponent }\end{array}$ & $\begin{array}{l}\text { Mechanism of ac } \\
\text { conduction }\end{array}$ & References \\
\hline Bulk $\mathbf{S b}_{2} \mathbf{S}_{3}$ & $303-393$ & $10^{2}-10^{6}$ & $0.83-0.79$ & $\begin{array}{l}\text { correlated barrier } \\
\text { hopping }\end{array}$ & $\begin{array}{l}\text { The present } \\
\text { work }\end{array}$ \\
\hline $\mathrm{Sb}_{2} \mathrm{~S}_{3}$ thin film & $303-373$ & $10^{2}-10^{5}$ & $1-0.7$ & $\begin{array}{l}\text { correlated barrier } \\
\text { hopping }\end{array}$ & [42] \\
\hline $\begin{array}{l}\mathrm{Sb}_{2} \mathrm{~S}_{3} \text { sprayed } \\
\text { thin film }\end{array}$ & $598-698$ & $5-13 \times 10^{5}$ & $0.79-0.49$ & $\begin{array}{l}\text { correlated barrier } \\
\text { hopping }\end{array}$ & [43] \\
\hline
\end{tabular}

Table (2): Values of density of localized states, $N\left(E_{F}\right)$, for $S_{b_{2}} S_{3}$ at different temperatures

\begin{tabular}{ccccccc}
\hline $\mathbf{T}(\mathrm{K})$ & $\mathbf{3 0 3}$ & $\mathbf{3 2 3}$ & $\mathbf{3 4 3}$ & $\mathbf{3 7 3}$ & $\mathbf{3 8 3}$ & $\mathbf{3 9 3}$ \\
\hline $\mathrm{N}\left(\mathrm{E}_{\mathrm{F}}\right) \cdot \mathbf{1 0 ^ { 1 8 }}\left(\mathrm{eV}^{-1} \mathbf{c m}^{-3}\right)$ & 8.69 & 9.23 & 9.43 & 10.21 & 11.21 & 12.09 \\
\hline
\end{tabular}

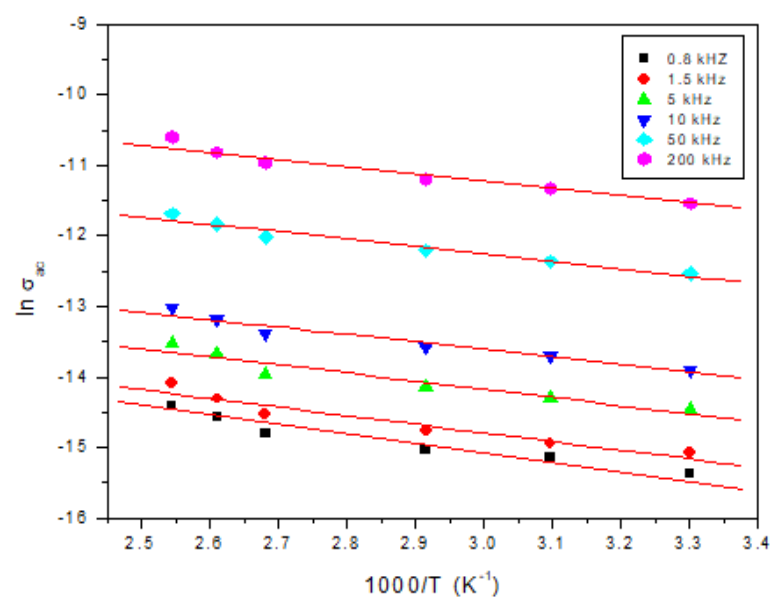

Fig. (10): The variation of $\ln \sigma_{\mathrm{ac}}(\omega)$ as a function of 1000/T for $\mathrm{Sb}_{2} \mathrm{~S}_{3}$ at different frequencies

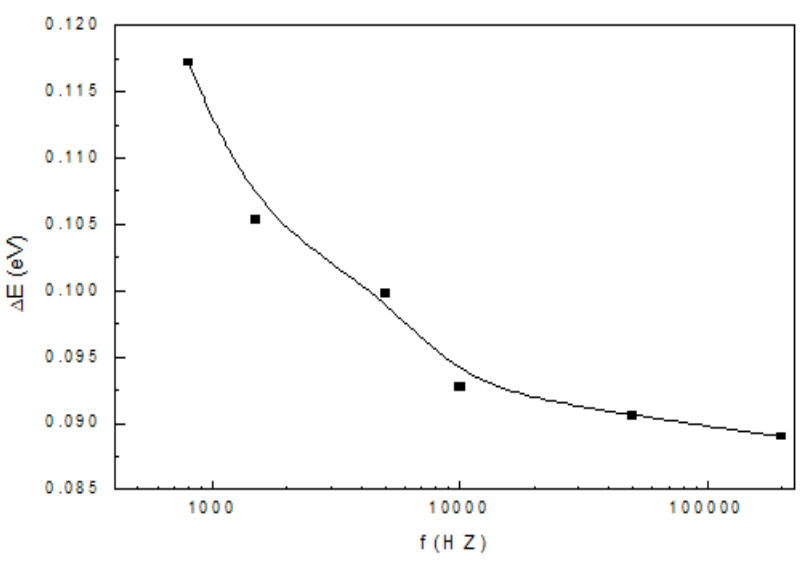

Fig. (11): The variation of $\Delta E$ for $\mathrm{Sb}_{2} \mathrm{~S}_{3}$ against frequency Arab J. Nucl. Sci. \& Applic. Vol. 53, No. X (2020) 


\section{Conclusion}

The structural features of the investigated $\mathrm{Sb}_{2} \mathrm{~S}_{3}$ powder were analyzed by XRD technique. The $\mathrm{Sb}_{2} \mathrm{~S}_{3}$ was found to be consistent with an orthorhombic system with lattice parameters $\mathrm{a}=$ $14.20 \AA, b=11.47 \AA$ and $c=7.47 \AA$. The major diffraction peak corresponds to the preferred orientation of (401). The powder of $\mathrm{Sb}_{2} \mathrm{~S}_{3}$ showed particles of irregular shape which were distributed over the surface in agglomerates. Dielectric properties and ac conductivity of bulk $\mathrm{Sb}_{2} \mathrm{~S}_{3}$ were studied at various temperatures and frequencies. The dielectric constant and dielectric loss decrease with increasing the frequency and increase by increasing the temperature. $\mathrm{M}^{\prime}$ has small values at low frequencies and $\mathrm{M}^{\prime \prime}$ increases with increasing the frequency which reaches a maximum value and decreases with the further raise in the frequency values. The ac conductivity of bulk $\mathrm{Sb}_{2} \mathrm{~S}_{3}$ increased with the increases in the frequency as $\sigma_{\mathrm{ac}}(\omega)=\mathrm{G} \omega^{\mathrm{s}}$ and it could be explained according to the correlated barrier hopping model. The ac conductivity displayed a thermally activated process from its relation with temperature. Activation energy for ac conduction was calculated and displayed a decrease by increasing frequency from $117 \mathrm{meV}$ at $800 \mathrm{~Hz}$ to $89 \mathrm{meV}$ at $200 \mathrm{kHz}$. Moreover, as the temperature increases, the density of localized states rises from $8.69 \times 10^{18}$ to $12.09 \times$ $10^{18} \mathrm{eV}^{-1} \cdot \mathrm{cm}^{-3}$ as the temperature increases at a certain frequency.

\section{References}

1. Escorcia-García, J., Becerra, D., Nair, M. T. S. and Nair, P. K., Thin Solid Films 569 (2014) 28.

2. Arun, P. and Vedeshwar, A.G., J. Mater. Sci. 31 (1996) 6507.

3. Ibuke, S. and Yochimatsu, S., J. Phys. Soc. Jpn. 10 (1955) 549

4. Nair, M.T.S., Pena, Y., Campos, J., Garcia, V.M. and Nair, P.K., J. Electrochem. Soc. 145 (1998) 2113.

5. Rajpure, K.Y. and Bhosale, C.H., Materials Chemistry and Physics 64 (2000) 14.

6. Tsopelas, C., J. Nucl. Med. 42 (2001) 46.

7. Zhang, H., Hu, C., Ding, Y. and Lin, Y., J. Alloy. Compd. 625 (2015) 90.
8. Moon, S., Itzhaik, Y., Yum, J., Zakeeruddin, S.M., Hodes, G. and Grätzel, M., J. Phys. Chem. Lett. 1 (2010) 1524.

9. Malakooti, R., Cademartiri, L., Migliori, A., and Ozin, G. A., J. Mater. Chem. 18 (2008) 66.

10. Petzelt, J. andGriga, J. s, Ferroelectrics 5 (1973) 59.

11. Fujita, T., Kurita, K., Takiyama, K. and Oda, T., J. Phys. Soc. Japan 56 (10) (1987) 3734.

12. Grigas, I.P. and Karpus, A.S., Sov. Phys. Sol. Stat. 9 (1968) 2270

13. Grigas, J., Zadoroznaja, L.A., Liachovitskaja, V.A. and Orliukas, A., Lietuvos Fizikos Rinkinys

(Lithuanian J. Phys.), 16 (1976) 833.

14. Savadogo, O. and Mandal, K.C., Sol. Energy Mater. Sol. Cells 26 (1992) 117.

15. Rajpure, K.Y. and Bhosale, C.H., Mater. Chem. Phys. 64 (2000) 70.

16. Ito, S., Tsujimoto, K., Nguyen, D. C., Manabe, K. and Nishino H., Int. J. Hydrogen Energy 38 (2013) 16749.

17. You, M. S., Lim, C. S., Kwon D. H., Heo, J. H., Im S. H. and Chae, K. J., Org. Electron. physics, Mater. Appl. 21 (2015) 155.

18. Messina, S., Nair, M.T.S. and Nair, P.K., Thin Solid Films 515 (2007) 5777.

19. Perales, E., Lifante, G., Agullo-Rueda, F. and De las Hares, C., J. Phys. D: Appl. Phys .40 (2007) 2440.

20. Krishnan, B., Arato, A., Cardenas E., Das Roy, T.K. and Castillo, G.A., Appl. Surf. Sci. 254 (2008) 3200

21. Aousgi, F. and Aousgi, M. X., Journal of Optoelectronics and Advanced Materials 12 (2010) 227.

22. Medina-Montes, M.I., Montiel-González, Z., Mathews, N.R. and Mathew, X., Journal of Physics and Chemistry of Solids (2017).

23. Ghosh, C., B.P. Varma, Solid State Communications, 31 (1979) 683.

24. Abdelmoneim, H.M., Indian J. Pure Appl. Phys. 48 (2010) 562.

25. A. Hanumaion, T. Bhimosankaram, S.V. Suryanarayan, g. Kumar, Bull. Mater. Sci. 17 (1997) 405 
26. Arun, P. and edeshwar, A.G. V, J. Mater. Sci. 31 (1996) 6507.

27. Mathew, N. J., Oommen, R., Rajalakshmip, U. and Sanjeeviraja C., Chalcogenide Letters 8(7) (2011) 441.

28. EL-Shazly, A.A., Seyam, M.A.M., ELSamanoudy, M.M., Ammar, A.H. and Assim, E.M., Appl. Sur. Sci. 198 (2002) 129.

29. Hill, N.E., Vaughan, W.E., Price and M. Davies, A.H., Dielectric Properties and Molecular Behaviour, Van Nostrand Reinhold Company, London (1969).

30. Srivaslava, K. K., Kumar, A., Panwar, O. S. and Lakshminarayan, K. N., J. Non-Cryst. Solids 33 (1979) 205.

31. Barsoum, M., Fundamentals of ceramicsI, New York: McGraw-Hill 543(1977).

32. Stevels, J. M., The electrical properties of glass, in Handbuch der Physik, Vol. edited by S. Flügge ,Springer, Berlin (1957).

33. Farid, A.M., Bekheet, A.E., Vacuum 59 (2000) 932.

34. Mathew, N. J., Oommen, R. and Rajalakshmi, U. P., Chalcogenide Letters 7 (2010) 701.

35. Fouad, S.S., Bekheet, A.E., and Farid, A.M., Physica B 322 (2002)163.

36. Kaiser, M., Physica B 407 (2012) 610.

37. Moynihan, C.T.,Solid State Ionics 105 (1998) 175.

38. Jonscher, A.K., Universal Relaxation Law (Chelsea Dielectrics Press, London, (1996).
39. Chen, R.H., Chang, R.Y. and Shern, S.C., J. Phys. Chem. Solids 63 (2002) 2069.

40. Tiwari, J. P. and Shahi, K., Philosophical Magazine 87 (2007) 4475.

41. Boughalmi, R., Boukhachem, A., Kahlaoui, M., Maghraoui, H. and Amlouk, M., Materials Science in Semiconductor Processing 26 (2014) 593.

42. Jonscher, A. K., Nature 267 (1977) 673.

43. Pollak, M., Philos. Mag. 23 (1971) 519.

44. Pollak, M. and Geballe, T.H., Phys. Rev. B 22 (1961) 1742.

45. Pollak, M. and Pike,, G.E., Phys. Rev. Lett. 28 (1972) 1449.

46. Elliott, Mag. B 36 (1978) 1291.

47. S.R. Elliott, Philos Mag. B 37 (1978) 135.

48. Shimakawa K. Philo.s Mag. 46 (1982)123.

49. I.G. Austin, N.F. Mott, Adv. Phys. 18 (1969) 41.

50. V.K. Bahatnagar, K.L. Bhatiam, J. Non-Cryst. Solids 119 (1990) 214.

51. M.M. El-Nahass, H.A.M. Ali, Solid State Communications 152 (2012) 1084.

52. M.M. El-Nahass, A.A. Attia, G.F. Salem, H.A.M. Ali n, M.I. Ismail, Physica B 434 (2014) 89-94.

53. A.E. Bekheet, Physica B 403 (2008) 4342. 